\title{
Psychometric Characteristics of Carver and White's BIS/BAS Scales in Dutch Adolescents and Their Mothers
}

\section{Rongqin Yu , Susan J. T. Branje, Loes Keijsers \& Wim H. J. Meeus}

To cite this article: Rongqin Yu, Susan J. T. Branje , Loes Keijsers \& Wim H. J. Meeus (2011) Psychometric Characteristics of Carver and White's BIS/BAS Scales in Dutch Adolescents and Their Mothers, Journal of Personality Assessment, 93:5, 500-507, DOI: 10.1080/00223891.2011.595745

To link to this article: https://doi.org/10.1080/00223891.2011.595745

曲 Published online: 22 Aug 2011.

Submit your article to this journal $\widetilde{ }$

Џ Article views: 567

Q View related articles ¿

7 Citing articles: 18 View citing articles 5 


\title{
Psychometric Characteristics of Carver and White's BIS/BAS Scales in Dutch Adolescents and Their Mothers
}

\author{
RongQin Yu, Susan J. T. Branje, Loes KeIJSERS, AND Wim H. J. MEeuS \\ Research Centre Adolescent Development, Utrecht University, The Netherlands
}

\begin{abstract}
The psychometric characteristics of Carver and White's (1994) BIS/BAS scales were examined in 2 groups of Dutch adolescents (497 early adolescents and 237 middle adolescents, $M_{\mathrm{Age}}=13.0$ years and 16.4 years, respectively $)$ and their middle-aged mothers $\left(M_{\mathrm{Age}}=45.2\right.$ years; $N=$ 734). Confirmatory factor analyses revealed an acceptably fitting 2-factor model for adapted BIS /BAS scales in all 3 groups, reflecting separate BIS and BAS factors. Reliabilities of the 2 scales were satisfactory. The results supported the convergent validity of BIS and BAS scales. BIS was positively correlated with internalizing problem behaviors and neuroticism. BAS was positively correlated with externalizing problem behaviors and extraversion. The discriminant validity of the BIS/BAS scales received mixed support in our data. BIS was negatively correlated with extraversion, and BAS was not correlated with depression. However, BIS was also found to be correlated with externalizing problem behaviors, and BAS was positively correlated with neuroticism. In sum, the scales are suitable for use in research settings, but caution is advocated in application for clinical practice.
\end{abstract}

Gray's (1987) reinforcement sensitivity theory has received increasing attention over the past decades, and is now one of the most influential biological personality theories. This theory posits that two main brain systems regulate approach and withdrawal behaviors in response to environmental stimuli. The behavioral inhibition system (BIS) is an aversive motivational system in response to novel or threatening cues. It is thought to alert individuals to the possibility of punishment or frustrative nonreward. The activation of this system causes inhibition of movement toward an intended goal. Parallel to the BIS is the behavioral activation system (BAS). This is an appetitive motivational system in response to signals of impending reward or nonpunishment. The activation of this system provokes approach behavior toward desired goals.

Carver and White (1994) developed the BIS/BAS scales to measure these constructs. The BIS/BAS scales are considered to be the most successful contribution measuring the fundamental components of Gray's theory (Smillie, Jackson, \& Dalgleish, 2006). The psychometric properties of the BIS/BAS scales have been tested in a considerable number of studies, predominantly among young college students. These studies have yielded mixed findings using different techniques.

Exploratory factor analyses (EFAs) in college students have shown a relatively consistent picture across studies. An EFA by Carver and White (1994) supported a four-factor structure among undergraduate students, including one BIS factor and three BAS factors, labeled Reward Responsiveness, Drive, and Fun Seeking. This four-factor structure was replicated among college students through EFA, both with the original version of the scales (Heubeck, Wilkinson, \& Cologon, 1998; Ross, Millis, Bonebright, \& Bailley, 2002) and translated versions in Dutch and Polish (Franken, Muris, \& Rassin, 2005; Müller \&

Received April 26, 2010; Revised December 6, 2010.

Address correspondence to Rongqin Yu, Research Centre Adolescent Development, Utrecht University, P.O. Box 80.140, 3508 TC Utrecht, The Netherlands; Email: r.yu@uu.nl
Wytykowska, 2005), as well as with a Russian version in which some items were deleted (Knyazev, Slobodskaya, \& Wilson, 2004).

Confirmatory factor analyses (CFAs) using undergraduate student samples have shown less consistent support for a fourfactor structure, however. Although some studies have found that a four-factor model provides a better fit to the data than a two-factor model, namely BIS and BAS (Cooper, Gomez, \& Aucote, 2007; Leone, Perugini, Bagozzi, Pierro, \& Mannetti, 2001; Ross et al., 2002; Sava \& Sperneac, 2006), others have found an adequately fitting four-factor model only when some items were removed from the scale (Cogswell, Alloy, van Dulmen, \& Fresco, 2006). In addition, one study reported that its four-factor model fits the data poorly. The comparative fit index (CFI) was .82 (Caci, Deschaus, \& Bayle, 2007). Moreover, two studies claimed that their data adequately or marginally fit the four-factor model, but the CFIs were .83 and .80 (Franken et al., 2005; Heubeck et al., 1998).

Furthermore, studies drawing on adult samples have revealed mixed findings. In particular, EFAs on a community sample and among company employees have indicated that a two-factor solution (i.e., BIS and BAS) was more appropriate than a fourfactor solution (Jorm, Henderson, Jacomb, Korten, \& Rodgers, 1999; Van der Linden, Beckers, \& Taris, 2007), leading some authors to suggest that the three BAS scales actually tap into the same underlying construct (Van der Linden et al., 2007). Overall, there is thus contradictory evidence regarding the inherent structure of the BIS/BAS scales. Based on psychometric grounds, caution is already warranted by some researchers in the continued use of the scales (Cogswell et al., 2006). Thus, further investigation of the BIS/BAS scales is urgently needed.

Although the relevance of Gray's theory to children and adolescents has become apparent in recent years, only a few studies have investigated the factor structure of the scales in these groups. One EFA study among Dutch children 10 years old found support for a two-factor structure reflecting separate BIS and BAS scales, but not for a four-factor structure (Muris, Meesters, De Kanter, \& Timmerman, 2005). The other study 
on Norwegian children, ages 11 and 12, reported three factors with two BAS scales and one BIS scale (Bjornebekk, 2009). Among 12- to 16-year-old adolescents in Australia (Cooper et al., 2007), a four-factor structure was obtained from CFA, similar to the structure attained among college students included in the same study. To our best knowledge, however, the latter study is the only one on adolescents, and also the only study that has tested the similarity of the factor structure among different age groups. No CFA studies have yet assessed the factorial structure of the BIS/BAS scales among non-English-speaking adolescents (e.g., in the Netherlands). Additionally, no study has compared the factor structure between different stages of adolescence, nor between adolescents and their mothers. Because adolescents are in the period of salient development (Lerner \& Steinberg, 2004), these comparisons might help to provide more insight into whether the BIS/BAS scales could be applied to longitudinal studies assessing different stages of adolescence and to intergeneration transmission research on adolescents and middle-aged adults.

Besides the factor structure of the BIS/BAS scales, their external validity is important to consider. Previous studies have found that the BIS scale correlated highly with neuroticism, whereas the BAS scales correlated with extraversion in both clinical and normal samples (Carver \& White, 1994; Heubeck et al., 1998; Smits \& Boeck, 2006; Van der Linden et al., 2007). BAS scales were also found to be correlated with impulsivity (Knyazev et al., 2004). Further, BIS and BAS were associated with different types of problem behaviors in early adult and child samples (Campbell-Sills, Liverant, \& Brown, 2004; Johnson, Turner, \& Iwata, 2003; Jorm et al., 1999). In particular, BIS was positively related to internalizing problem behaviors, such as depression and anxiety, whereas the BAS scales were positively correlated with externalizing problem behaviors, such as drug use or aggression (Johnson et al., 2003; Muris et al., 2005), although in one study, BIS's correlation with aggression was higher than BAS's correlation with aggression (Muris et al.). To examine whether the BIS/BAS scales have satisfactory validity in other samples, such as adolescents and middleaged adults, it is necessary to replicate these previous findings.

This study had two main objectives. The first was to test the factor structure of Carver and White's (1994) BIS/BAS scales in two groups of Dutch adolescents and their mothers. The factorial similarity between different age groups was also tested. The second aim was to examine the convergent and discriminant validity of these scales, by examining how the BIS/BAS scales correlate with particular problem behaviors and personality traits.

\section{METHOD}

\section{Participants}

Participants came from an ongoing longitudinal study, Research on Adolescent Development and Relationships (RADAR), containing two cohorts. RADAR Young included 497 Dutch early adolescents (57\% boys), with a mean age of 13.0 years $(S D=0.52)$. RADAR Old included participants from a group of 237 Dutch middle adolescents (46\% boys), with a mean age of 16.4 years $(S D=0.73)$. RADAR Young and RADAR Old were recruited from various, randomly selected Dutch elementary schools and high schools, respectively. Mothers of these two adolescent groups also participated in the studies, with a mean age of 45.2 years $(S D=4.57, N=734)$. Because these studies were both designed to assess full families (i.e., both parents, adolescents, and a sibling), families were not eligible for participation when they only had one child.

\section{Procedure}

A description of the study was sent to adolescents and their parents. Confidentiality and anonymity for participating in the studies were assured. After giving informed consent, adolescents and mothers completed various questionnaires. Both of them received $€ 15$ as a reward for their participation.

\section{Measures}

BIS and BAS. The BIS/BAS scales (Carver \& White, 1994) make up a 20-item self-report questionnaire. A Dutch version of the scales was employed, translated from English to Dutch and then back-translated to English without reference to the original text. The back-translated version was compared to the original scales to assure consistency. Seven BIS items assess people's emotional responses to impending punishing events (e.g., "I feel pretty worried or upset when I think or know somebody is angry at me"). Thirteen BAS items tap individuals' emotional and behavioral responses to potentially rewarding events (e.g., "When I see something I want, I feel excited right away"; "If I see a chance to get something I want, I move on it right away"). Both adolescents and mothers were asked to respond to the items, with reference to themselves, using 4-point Likert scales that ranged from 1 (strongly disagree) to 4 (strongly agree). Detailed information regarding reliabilities and validities of these scales in our sample is provided in the Results section.

Adolescent externalizing behaviors. Externalizing problems were measured both through mother reports of their child's behaviors and through adolescents' self-reports. Mothers filled in the Child Behavior Check List (CBCL; Achenbach, 1991) consisting of 118 items addressing youths' problem behaviors. In this study, 33 items of this scale were used to assess adolescents' externalizing problem behaviors including delinquency (13 items; e.g., "Sets fires") and aggression (20 items; e.g., "Fights a lot") during the last 6 months, with a 3-point scale $(0=$ not true, $1=$ sometimes true, $2=$ true $)$. The validity and reliability of this measure has been shown to be adequate (Achenbach). Cronbach's alphas for this scale were .91 and .89 among early and middle adolescents, respectively.

Adolescents filled out the Youth Self Report (YSR; Verhulst, Van der Ende, \& Koot, 1997), which is the self-report version of the CBCL. This scale consists of 102 items, of which 30 items were employed to assess externalizing problem behaviors including delinquency (11 items; e.g., "I set fires") and aggression (19 items; e.g., "I fight a lot"). Participants responded to the questions on a 3 -point Likert scale $(0=$ never, $1=$ sometimes, $2=$ often). Good validity and test-retest reliability have been established in other studies (Verhulst et al., 1997). Cronbach's alphas were .89 and .85 among early and middle adolescents, respectively.

Depression. To assess adolescents' depressive symptoms, we used Reynolds's (2002) Adolescent Depression Scale (2nd ed. [RADS-2]). This self-report measure consists of 30 items (e.g., "I am sad"). Youths answered these questions using a 4-point scale ranging from 1 (almost never) to 4 (usually). A 
previous study has shown that this scale has good reliability and validity (Reynolds, 2002). In this study, Cronbach's alphas were .89 for early adolescents and .88 for middle adolescents.

Anxiety. To measure adolescents' anxiety symptoms, we used the Screen for Child Anxiety Related Emotional Disorder (SCARED; Birmaher et al., 1997), which is a 38-item selfreport questionnaire (e.g., "I am nervous"). Adolescents rated how frequently they had experienced each symptom on a 3-point scale $(0=$ almost never, $1=$ sometimes, $2=$ often $)$. A previous study demonstrated good reliability and validity among Dutch adolescents (Hale, Raaijmakers, Muris, \& Meeus, 2005). In this study, Cronbach's alpha was .92 among both early and middle adolescents.

Mothers' problem behaviors. The Adult Self Report (Achenbach \& Rescorla, 2003) including 74 items on various problem behaviors was used to tap mothers' problem behaviors. This study employed 33 of the 74 items, including an 18-item anxious/depressed scale (e.g., "I feel lonely") and a 15-item aggression scale (e.g., "I blame others for my problem"). Mothers used a 3-point scale ranging from 0 (never) to 2 (often/mostly true) to rate the extent to which a series of statements described their behavior over the past 6 months. A prior study established good psychometric properties of this scale (Achenbach $\&$ Rescorla). In this study, Cronbach's alphas for mothers were .85 for the anxious/depressed scale, and .80 for the aggression scale, respectively.

Personality traits. A shortened Dutch version of Goldberg's Big Five questionnaire (Gerris et al., 1998; Goldberg, 1992) assessed the personality dimensions Extraversion, Agreeableness, Conscientiousness, Neuroticism, and Openness to Experience of adolescents and their mothers. Both adolescents and mothers rated their own personality on a scale ranging from 1 (completely untrue) to 7 (completely true). Prior studies using the same translated scale indicate that it has acceptable reliability and validity in the estimation of adolescents' personality traits (Branje, van Lieshout, \& Gerris, 2007). This study employed the subscales for Extraversion (6 items; e.g., "Talkative") and Neuroticism (6 items; e.g., "Irritable"). Reliabilities in all samples were acceptable, ranging from .79 to .91 for Extraversion, and from .82 to .87 for Neuroticism.

\section{RESULTS}

To answer our first research question, we ran CFA in Mplus (Muthén \& Muthén, 2007) to test the two-factor model, including BIS and BAS, against the four-factor model that included BIS, BAS-Reward Responsiveness, BAS-Drive, and BAS-Fun Seeking. Robust maximum likelihood estimation was used (Satorra \& Bentler, 1994). All latent factors were allowed to correlate. The goodness of fit of the models was assessed through multiple criteria: CFI, root mean squared error of approximation (RMSEA), and standardized root mean square residual (SRMR). CFI values of .90 and above, and RMSEA and SRMR values of less than .08 are considered an acceptable fit (Hu \& Bentler, 1999; Kline, 2005). Additionally, we assessed the reliability of each scale in CFA (Raykov, 2004).

The initial two-factor and four-factor models did not meet a common fit standard (i.e., CFI < .90). In particular, in early adolescents, model fit for the two-factor model was $\chi^{2}(n=497$,
$169)=487.91, \mathrm{CFI}=.77, \mathrm{RMSEA}(\mathrm{CI})=.06(.06, .07), \mathrm{SRMR}$ $=.07$, Bayesian Information Criterion $(\mathrm{BIC})=21806.82$. For the four-factor model the fit was $\chi^{2}(n=497,164)=425.40$, $\mathrm{CFI}=.80, \mathrm{RMSEA}(\mathrm{CI})=.06(.05, .06), \mathrm{SRMR}=.07, \mathrm{BIC}$ $=21944.80$. In middle adolescents, model fit for the two-factor model was $\chi^{2}(n=237,169)=502.97, \mathrm{CFI}=.71$, RMSEA $(\mathrm{CI})=.09(.08, .10), \mathrm{SRMR}=.10, \mathrm{BIC}=10263.84$, and for the four-factor model the fit was $\chi^{2}(n=237,164)=412.25$, $\mathrm{CFI}=.78$, RMSEA $(\mathrm{CI})=.08(.07, .09), \mathrm{SRMR}=.08, \mathrm{BIC}$ $=10190.66$. In mothers, model fit for the two-factor model was $\chi^{2}(n=734,169)=886.45, \mathrm{CFI}=.77, \mathrm{RMSEA}(\mathrm{CI})=.08$ $(.07, .08)$, SRMR $=.08, \mathrm{BIC}=32398.19$, and for the fourfactor model the fit was $\chi^{2}(n=734,164)=777.87, \mathrm{CFI}=.80$, RMSEA $(\mathrm{CI})=.07(.07, .08), \mathrm{SRMR}=.07, \mathrm{BIC}=32309.14$.

To improve the model fit, first we looked at the factor loading of each item. We designated an item as "poor" if it failed to achieve a loading of at least .30 on its hypothesized factor. CFA revealed that the two reverse-coded items consistently did not load adequately on the hypothesized factor BIS. The magnitudes of factor loadings for Item 12 ("Even if something awful is about to happen for me, I rarely experience fear or nervousness") and Item 18 ("Compared to my friends, I have very few fears") were small. In particular, for early adolescents, in both the two-factor and the four-factor models, the factor loadings of Items 12 and 18 were .18 and .07 , respectively. Factor loadings for all the other items were higher than .30 , ranging from .31 to .68 in the twofactor model, and from .34 to .65 in the four-factor model. Additionally, previous studies have also removed these two items along with some other items because of noticeably low factor loadings (Campbell-Sills et al., 2004; Cogswell et al., 2006), and one study has suggested that these two reversed items were too difficult for young children, therefore they simplified or changed these items in their study (Muris et al., 2005). Therefore, these two items were removed from subsequent analyses. The correlations between factor scores with these two items included and with these two items deleted were .996 in early adolescents, .993 in middle adolescents, and .988 in the mother group.

\section{Two- and Four-Factor Models on the Adapted Scales}

After deletion of these two items, the two-factor and fourfactor models still did not meet a common fit standard (i.e., CFI < .90). Specifically, in early adolescents, model fit for the two-factor model was $\chi^{2}(n=497,134)=359.91, \mathrm{CFI}=.82$, RMSEA $(\mathrm{CI})=.06(.05, .07), \mathrm{SRMR}=.06, \mathrm{BIC}=19498.35$, and for the four-factor model the fit was $\chi^{2}(n=497,129)=$ $315.56, \mathrm{CFI}=.85$, RMSEA $(\mathrm{CI})=.06(.05, .06), \mathrm{SRMR}=$ $.06, \mathrm{BIC}=19475.08$. In middle adolescents, model fit for the two-factor model was $\chi^{2}(n=237,134)=384.58, \mathrm{CFI}=.75$, RMSEA $(\mathrm{CI})=.09(.08, .10), \mathrm{SRMR}=.09, \mathrm{BIC}=9137.80$, and for the four-factor model the fit was $\chi^{2}(n=237,129)=$ 296.63, CFI $=.83$, RMSEA $(\mathrm{CI})=.07(.06, .09)$, SRMR $=$ $.07, \mathrm{BIC}=9067.11$. In mothers, model fit for the two-factor model was $\chi^{2}(n=734,134)=709.98, \mathrm{CFI}=.80$, RMSEA $(\mathrm{CI})=.08(.07, .08), \mathrm{SRMR}=.07, \mathrm{BIC}=28883.25$, and for the four-factor model the fit was $\chi^{2}(n=734,129)=608.09$, $\mathrm{CFI}=.83$, RMSEA $(\mathrm{CI})=.07(.07, .08), \mathrm{SRMR}=.06, \mathrm{BIC}=$ 28800.92. We therefore pursued modified models, in which we allowed the error covariance between items within latent factors to correlate if the modification indexes implied that adding the correlations would significantly decrease the chi-square value. 
TABLE 1.-Fits indexes of modified two-factor and four-factor models and reliabilities for BIS/BAS scales in adolescents and mothers.

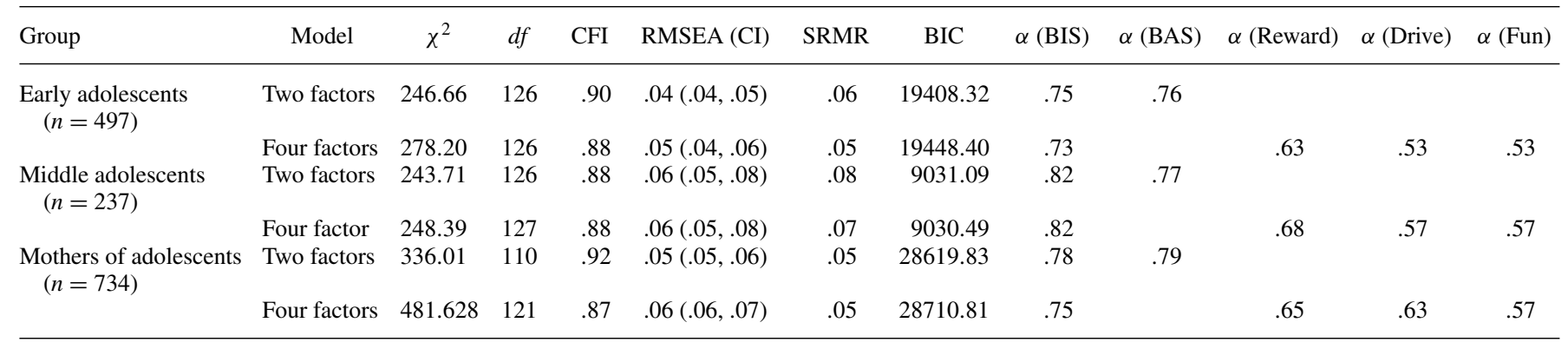

Note BIC $=$ Bayesian information criterion CFI $=$ comparative fit index RMSEA $=$ root mean squared error of approximation; SRMR $=$ standardized root mean square residual.

Modifications were made simultaneously. To improve the model fits for the two-factor models, error terms between Items 3 and 11,3 and 20,6 and 19, and 10 and 19 were correlated in both early and middle adolescents (see the content of the items in the Appendix). Additionally, in early adolescents, error terms between Items 7 and 8, 8 and 10, 10 and 11, and 1 and 16 were also allowed to be correlated, and in middle adolescents, error terms between Items 3 and 10, 3 and 19, 6 and 14, and 13 and 14 were allowed to be correlated. In the mother group, all the modifications previously listed except the correlation between error terms of Items 8 and 10 were applied. In addition, error terms between Items 1 and 2, 2 and 9, 4 and 8, 6 and 7,6 and 10, 7 and 13,8 and 15, 2 and 16, 7 and 17, 11 and 19,6 and 20 , and 11 and 20 were allowed to be correlated in the mother group.

We also applied modifications to improve the model fit of the four-factor models. In early adolescents, error terms between Items 1 and 16, 6 and 19, and 3 and 20 were allowed to be correlated. In middle adolescents, error terms between Items 6 and 19, and 3 and 20 were allowed to be correlated. In the mother group, all modifications used in early and middle adolescents were applied. Additionally, we allowed five other pairs of error terms to be correlated: error terms between Items 1 and 2, 2 and 9,6 and 11, 2 and 16, and 11 and 19.

The fit indexes are presented in Table 1 . The modified fourfactor models did not achieve adequate fit in all three groups. Also, reliabilities of the BAS scales were low, as no Cronbach's alpha was higher than .70 (the threshold for acceptable reliability according to Nunnelly \& Bernstein, 1994). Given the inadequate fit and low reliabilities, we considered a four-factor solution to be inappropriate.

The fit indexes of the modified two-factor models were more acceptable than those of the four-factor models in early adolescents and mothers for all fit measures. The indexes of the two-factor model and the four-factor model were comparable in middle adolescents. However, the two-factor model was more parsimonious, and the reliabilities of the separate BIS and BAS scales were acceptable in all groups. Therefore, the two-factor model was preferred over the more complex, and slightly worsefitting four-factor model (Kline, 2005).

\section{Group Invariance}

Subsequently, the factor structure was compared between early and middle adolescents, and between adolescents and mothers. We tested four levels of group invariance, including configural, metric, factor variance, and factor covariance invari- ance. First, a test of configural invariance examines whether the same subsets of items load on the same construct (i.e., latent factor) in different groups. That is, we tested whether the factor structure held across groups. This was tested by examining whether the unconstrained model (baseline model M0) had a good model fit, in which factor loadings, intercepts, and residual variances were set free (Cheung \& Rensvold, 2002). Second, to test metric invariance, and thus whether the strength of the associations between items and their underlying constructs (i.e., the factor loadings) were similar for different groups, we compared the baseline model (M0) with a model in which factor loadings of the items on the latent factors were constrained across groups (M1; Cheung \& Rensvold). Third and fourth, we tested whether the variances of the factors and the covariances between the factors were similar across groups. The invariance of these factor variances and covariances was tested by comparing the metric model (M1) with models in which factor variances (M2) and factor covariances (M3), respectively, were constrained across groups. In these model comparisons, nonsignificant differences in chi-square model fit between the unconstrained and constrained models were considered as supporting group invariance.

Group invariance between early and middle adolescents. Table 2 shows the results of invariance tests across the two adolescent samples. M0 had an adequate model fit, which supported configural invariance. That is, in the early and middle adolescent samples, the same subsets of items were associated with the same constructs (i.e., BIS or BAS). There was no significant difference in model fit between this M0 and the full metric invariance model (M1), indicating that the factor loadings were similar across groups. There was a significant difference between M1 and the model in which factor variance was constrained across groups (M2), indicating that the range of responses on the BIS and/or BAS were significantly different across groups. Follow-up analyses, in which only BIS was constrained, revealed a significant difference (M2.1). When only BAS was constrained, however, there was no significant difference (M2.2). This implies that ranges of response to BAS were similar across samples, whereas they were different to BIS. There was also no significant difference between M1 and the model in which factor covariances were constrained (M3), indicating that the relationships among BIS and BAS were similar across these two groups. Thus, except for the BIS factor variance, the two-factor model did not differ between early and middle adolescents. 
TABLE 2.-Test of invariance for the BIS/BAS scales across early and middle adolescents.

\begin{tabular}{|c|c|c|c|c|c|c|c|}
\hline Model & $\chi^{2}$ & $d f$ & CFI & RMSEA & SRMR & $\begin{array}{l}\text { Delta } \\
\text { model }\end{array}$ & $p$ \\
\hline M0. Configural invariance & 460.10 & 242 & .91 & .05 & .06 & - & - \\
\hline $\begin{array}{l}\text { M1. Full metric invariance } \\
\text { (M0 with all factor } \\
\text { loadings constrained } \\
\text { equal) }\end{array}$ & 474.04 & 258 & .91 & .05 & .07 & M1-M0 & .60 \\
\hline $\begin{array}{l}\text { M2. Factor variances } \\
\text { invariance (M1 with all } \\
\text { factor variances } \\
\text { constrained equal) }\end{array}$ & 483.03 & 260 & .90 & .05 & .07 & M2.1-M1 & .01 \\
\hline $\begin{array}{l}\text { M2.1. Factor variances } \\
\text { invariance (M1 with only } \\
\text { BIS constrained equal) }\end{array}$ & 482.55 & 259 & .90 & .05 & .07 & M2.2-M1 & .00 \\
\hline $\begin{array}{l}\text { M2.2. Factor variances } \\
\text { invariance (M1 with only } \\
\text { BAS variances } \\
\text { constrained equal) }\end{array}$ & 474.20 & 259 & .91 & .05 & .07 & M2.2-M1 & .69 \\
\hline $\begin{array}{l}\text { M3. Factor covariance } \\
\text { invariance (M1 with all } \\
\text { factor covariance } \\
\text { constrained equal) }\end{array}$ & 476.37 & 259 & .91 & .05 & .07 & M3-M1 & .13 \\
\hline
\end{tabular}

Note. CFI = comparative fit index; RMSEA = root mean squared error of approximation; SRMR = standardized root mean square residual.

Group invariance between adolescents and mothers. We also tested the invariance of the model for adolescents and mothers. Two adolescent groups were combined in this analysis, as the two-factor models did not differ between them. The results supported configural invariance across adolescents and mothers. The fit indexes for the configural model (M0) were $\chi^{2}(n=1468,214)=562.82, p<.001$, CFI $=.93$, RMSEA $=$ .05 , SRMR $=.05$, which indicated that adolescents and mothers decompose into the same number of factors, with the same items associated with BIS and BAS, respectively. Metric invariance did not hold, as the configural model and full metric model differed significantly, $\left(\Delta \chi^{2}(N=1468)=48.06 ; \Delta d f=16 ; p\right.$ $=.00)$. Criteria for partial invariance were also not met. Hence, the strength of the relationship between each BIS/BAS item and the BIS/BAS factors (i.e., the factor loadings) was different for adolescents and mothers. Because the metric varied between adolescents and their mothers, the subsequent analyses for factor variance and covariance invariance were not conducted (Chen, 2002).

\section{Means and Correlations Among BIS and BAS}

The mean scores of BIS and BAS were similar across groups, ranging from $12.16(S D=3.48)$ to $13.38(S D=3.09)$ in BIS, and for BAS from $38.21(S D=5.81)$ to $39.88(S D=5.10)$. Mean scores and standard deviations of problem behaviors and personality traits are presented in Table 3 . The correlations between BIS and BAS were $.37(p=.00)$ in the early adolescent group, $.42(p=.00)$ in the middle adolescent group, and $.30(p$ $=.00)$ in the mother group.

\section{Convergent and Discriminant Validity}

Finally, we ran tests to assess the convergent and discriminant validity of the BIS/BAS scales. To examine convergent validity, we estimated correlations of BIS with internalizing problem behaviors and neuroticism, and correlations of BAS with ex-
TABLE 3.-Descriptive statistics for problem behaviors of adolescents and their mothers.

\begin{tabular}{|c|c|c|c|c|c|c|}
\hline & \multicolumn{2}{|c|}{$\begin{array}{c}\text { Early } \\
\text { adolescents } \\
(n=497)\end{array}$} & \multicolumn{2}{|c|}{$\begin{array}{c}\text { Middle } \\
\text { adolescents } \\
(n=237)\end{array}$} & \multicolumn{2}{|c|}{$\begin{array}{l}\text { Mothers of } \\
\text { adolescents } \\
(n=734)\end{array}$} \\
\hline & $M$ & $S D$ & $M$ & $S D$ & $M$ & $S D$ \\
\hline BIS & 12.23 & 2.90 & 12.16 & 3.48 & 13.38 & 3.09 \\
\hline BAS & 39.88 & 5.10 & 35.54 & 4.92 & 38.21 & 5.81 \\
\hline Anxiety $^{a}$ & 51.06 & 9.50 & 47.72 & 9.28 & 4.45 & 4.61 \\
\hline Depression & 49.05 & 11.97 & 47.98 & 11.95 & & \\
\hline $\begin{array}{l}\text { Aggression/ } \\
\text { Delinquency } \\
\text { (Self-Report) }\end{array}$ & 10.60 & 7.15 & 9.02 & 6.33 & 2.32 & 2.74 \\
\hline $\begin{array}{l}\text { Aggression/ } \\
\text { Delinquency } \\
\text { (Mother Report) }\end{array}$ & 8.97 & 7.84 & 5.90 & 6.27 & & \\
\hline Neuroticism & 26.42 & 6.61 & 27.69 & 7.01 & 24.96 & 7.03 \\
\hline Extraversion & 30.46 & 6.23 & 30.24 & 6.99 & 26.88 & 8.11 \\
\hline
\end{tabular}

Note. Adolescents' and mothers' personalities were assessed by Dutch version of Goldberg's Big Five questionnaire. Mothers' problem behaviors were measured by Adult Self Report. Adolescents' anxiety and depression were assessed by Screen for Child Anxiety Related Emotional Disorder and Reynolds Adolescent Depression Scale (2nd ed.), respectively. Adolescents' externalizing problem behaviors were measured by both self-report on Youth Self-Report and mothers' report on Child Behavior Checklist.

${ }^{a}$ For mothers, this refers to the combination of anxiety/depression symptoms.

${ }^{b}$ For mothers, this refers only to aggression.

ternalizing problem behaviors and extraversion. Significant and positive correlations were considered support for convergent validity, as these correlations would be hypothesized. We assessed the discriminant validity by examining the correlations of BIS with externalizing problem behaviors and extraversion, and of BAS with internalizing problem behaviors and neuroticism. Absence of these correlations was an indication of good discriminant validity, given that these correlations were not theoretically proposed. We also compared the differential magnitude of the correlations of BIS/BAS factors with problem behavior and personality traits through a $\mathrm{z}$ test. The $\mathrm{z}$ test is a generalization of Fisher's $z$ transformation procedure, which examines the differences between correlations of several concepts with a common variable (Meng, Rosenthal, \& Rubin, 1992). In our study, we compared the correlations of internalizing versus externalizing problem behaviors with the common variables BIS/BAS, and the correlations of neuroticism versus extraversion with the common variables BIS or BAS.

Correlations are presented in Table 4 . The results supported convergent validity, as BIS was positively correlated with internalizing problem behaviors and neuroticism. These correlations were significantly higher than the correlations of BIS with externalizing problem behaviors and extraversion, respectively. There was less support for the discriminant validity of BIS, as BIS was also positively associated with externalizing problem behaviors. These correlations were significantly lower than correlations between BIS and internalizing problem behaviors, however. There was support for BAS's convergent validity, as BAS was significantly but weakly correlated with externalizing problem behaviors and extraversion. There was also some support for the discriminant validity of BAS, considering it generally had nonsignificant correlations with internalizing problem behaviors. Moreover, BAS was significantly more strongly correlated with externalizing problem behaviors than with internalizing problem behaviors. Contrary to predictions, however, BAS 
TABLE 4.-Differential relations of BIS/BAS scales with problem behaviors in adolescents and mothers.

\begin{tabular}{|c|c|c|c|c|c|c|c|}
\hline Group & $\begin{array}{l}\text { BIS/BAS } \\
\text { Factor }\end{array}$ & Anxiety $^{a}$ & Depression & $\begin{array}{c}\text { Aggression/Delinquency } \\
\text { (Self-Report) }\end{array}$ & $\begin{array}{l}\text { Aggression/Delinquency } \\
\text { (Mother Report) }\end{array}$ & Neuroticism & Extraversion \\
\hline Early adolescents $(n=497)$ & $\begin{array}{l}\text { BIS } \\
\text { BAS }\end{array}$ & $\begin{array}{l}.50^{* *} \mathrm{a} \\
.03_{\mathrm{b}}\end{array}$ & $\begin{array}{l}.37^{* *} \mathrm{~b} \\
.03_{\mathrm{b}}\end{array}$ & $\begin{array}{l}.24^{* *}{ }^{\mathrm{c}} \\
.20^{* * *}{ }_{\mathrm{a}}\end{array}$ & $\begin{array}{l}.14^{*}{ }_{\mathrm{d}} \\
.17^{* *} \mathrm{a}\end{array}$ & $\begin{array}{l}.54^{* *}{ }_{1} \\
.13^{* *}{ }_{1}\end{array}$ & $\begin{array}{r}-.20^{* *}{ }^{2} \\
.08^{* *}{ }_{1}\end{array}$ \\
\hline Middle adolescents $(n=237)$ & $\begin{array}{c}\text { BIS } \\
\text { BAS }\end{array}$ & $\begin{array}{l}.61^{* *}{ }^{*}{ }^{a} \\
.19^{*}{ }^{a}\end{array}$ & $\begin{array}{l}.52^{* *}{ }_{\mathrm{a}} \\
.03_{\mathrm{b}}\end{array}$ & $\begin{array}{l}.17^{* *}{ }^{a} \mathrm{~b} \\
.16^{*}{ }_{\mathrm{a}}\end{array}$ & $\begin{array}{l}-.02_{\mathrm{c}}{ }^{a} \\
.12^{*}{ }_{\mathrm{a}}\end{array}$ & $\begin{array}{l}.70^{* * *}{ }_{1} \\
.35^{* *}{ }_{1}\end{array}$ & $\begin{array}{l}-.34^{* *}{ }^{*} \\
.11^{*}{ }_{2}\end{array}$ \\
\hline Mothers of adolescents ( $n=734$ ) & $\begin{array}{l}\text { BIS } \\
\text { BAS }\end{array}$ & $\begin{array}{l}.38^{* *}{ }_{a} \\
.01_{b}\end{array}$ & & $\begin{array}{l}.30^{* *}{ }_{\mathrm{b}} \\
.09^{*}{ }_{\mathrm{a}}\end{array}$ & & $\begin{array}{l}.38^{* *}{ }_{1} \\
.09^{*}{ }_{1}\end{array}$ & $\begin{array}{c}-.16^{* *}{ }_{2} \\
.05_{1}\end{array}$ \\
\hline
\end{tabular}

Note. Parameters in the same row but with different subscripts labeled with Alphabetic letters differ significantly in magnitude of relations with problem behaviors. Parameters in the same row but with different subscripts labeled with Arabic numbers differ significantly in magnitude of relations with personality traits. Adolescents' and mothers' personalities were assessed by Dutch version of Goldberg's Big Five questionnaire. Mothers' problem behaviors were measured by Adult Self Report. Adolescents' anxiety and depression were assessed by Screen for Child Anxiety Related Emotional Disorder and Reynolds Adolescent Depression Scale (2nd ed.), respectively. Adolescents' externalizing problem behaviors were measured by both self-report on Youth Self-Report and mothers' report on Child Behavior Checklist.

${ }^{a}$ For mothers, this refers to the combination of anxiety/depression symptoms. ${ }^{b}$ For mothers, this refers only to aggression.

${ }^{*} p<.05$.

${ }^{* *} p<.01$.

was also positively correlated with neuroticism in all groups and positively correlated with anxiety in middle adolescents. Further, the magnitudes of correlations between BIS and externalizing behaviors were comparable to correlations between BAS and externalizing problem behaviors in early and middle adolescents, and significantly higher than correlations between BAS and externalizing problem behaviors in the mother group.

\section{DISCUSSION}

In this study, the factor structure of Carver and White's (1994) BIS/BAS scales was tested among Dutch early and middle adolescents and their mothers. Two items were deleted because of low factor loadings. Poor fit statistics were obtained in both initial two-factor and four-factor models. After modifications, the four-factor models did not meet the conventional standards of model fit and reliabilities, but two-factor models were found to fit the data within acceptable ranges. The factor structure was comparable for early and middle adolescents, and also consistent with the structure found among mothers. The scales possessed satisfactory reliabilities across groups. This study also provided support for the convergent validity of BIS and BAS, indicated by their positive correlations with internalizing problem behaviors or externalizing problem behaviors, respectively. Limited support was also obtained for discriminant validity of the scales.

Our finding that a two-factor model was superior to a four-factor model contradicts some previous studies (Cooper et al., 2007; Leone et al., 2001; Muris et al., 2005; Ross et al., 2002; Sava \& Sperneac, 2006). One reason for these conflicting findings might lie in the samples used. Studies supporting the four-factor model have predominantly utilized college samples, and most prior studies on noncollege samples from the normal population have favored a two-factor model (Jorm et al., 1999; Van der Linden et al., 2007). Our results are consistent with findings from this latter collection of research. Additionally, our findings might reflect cultural differences. Although the number of Dutch studies is limited, existing evidence is in favor of a two-factor model. In addition to the aforementioned studies on Dutch children and company employees reporting a two-factor model (Muris et al., 2005; Van der Linden et al., 2007), one study assessing Dutch college students reported a four-factor model. However, the model fit did not meet conventional standards (CFI $=.84$; Franken et al., 2005). Further studies on more heterogeneous samples are needed to examine these possibilities. For instance, research comparing college and adult samples in the same study could be used to test the similarity in patterns of item endorsement between groups.

In addition, different methodological approaches have been used between studies to investigate the factor structure. For instance, some studies have used item parceling instead of itembased CFA to investigate the factor structure of the BIS/BAS scale (Leone et al., 2001; Smits \& Boeck, 2006). Different methods preclude direct comparisons across studies, but a previous study comparing item parceling and item-based CFA found that results with these two methods were similar (Hau \& Marsh, 2004). In our study, we investigated a trimmed scale (i.e., with items removed) on CFA. The high correlations between factor scores with two items included and with two items deleted implied that it was appropriate to compare our study to those using full BIS/BAS scales.

We removed two items, namely "Even if something awful is about to happen for me, I rarely experience fear or nervousness," and "Compared to my friends, I have very few fears," in our study. This is consistent with previous studies that removed these two items along with some others because of remarkably low factor loadings (Campbell-Sills et al., 2004; Cogswell et al., 2006). Further, one study on children has suggested that these two reversed items were too difficult for their participants, therefore these items were simplified or changed (Muris et al., 2005).

Our study demonstrated differential magnitudes of correlation between the BIS/BAS scales and different types of problem behaviors. Gray's (1987) theory hypothesizes that activation of BIS is more strongly associated with anxiety or depression. Consistent with this assumption, and with prior studies (Carver \& White, 1994; Jorm et al., 1999), we found strong correlations between BIS and these internalizing problem behaviors. Gray's theory also proposes that activation of BAS is related to "behavioral excess, in the sense of doing things that potentially lead to trouble" (Fowles, 1987, p. 421). Our study confirmed that BAS is significantly, albeit weakly, correlated with externalizing problem behaviors, namely delinquency and aggression. These findings provide further evidence for convergent validity of the scales. The discriminant validity of the BIS/BAS scales also received some support in our data. For instance, BIS was negatively correlated with extraversion across all groups, and BAS was not correlated with depression across all samples and 
also was not associated with anxiety in early adolescents and mothers. However, BIS was also positively correlated with externalizing problem behaviors, and the magnitudes were similar to those of correlations between BAS and externalizing behaviors. This association was also observed in an earlier study with Dutch children, however. It was reported that the correlations between BIS and aggression were higher than the correlations between BAS and aggression (i.e., $r=.29$ vs. $r=.13$ ). The authors suggested that BIS consists not only of sadness and fear, but also includes emotions such as anger and frustration that could contribute to aggression or delinquency (Muris et al., 2005). This is consistent with studies reporting comorbidity of internalizing and externalizing problem behaviors (Gjone \& Stevenson, 1997). In sum, the discriminant validity of the BIS/BAS scales needs further investigation.

The results of this study supported group invariance across early and middle adolescents. Not only were the number of latent factors equal across groups, but the factor loadings and covariance between BIS and BAS were also similar across early and middle adolescents. The results also supported configural invariance between adolescents and mothers, implying that the factorial structure of BIS/BAS scales is comparable across these two groups. These results, combined with results from testing of convergent and discriminant validity, imply that the revised BIS/BAS scales could be used, with caution, for future longitudinal studies of adolescents and also in research on intergenerational transmission between adolescents and their parents.

Despite the fact that we used multiple samples, to prevent sample-dependent solutions, there are some limitations of this study. One limitation is the cross-sectional design, which prevented us from exploring stability of the factor solution over time and from examining causal relations between BIS/BAS scales and problem behaviors. Longitudinal studies are needed to gain more insight into the direction of effects between these variables. The other limitation is that, because our samples were drawn from a normal population, the use of the revised version in a clinical sample requires further research.

In conclusion, our study revealed that a two-factor model fits the data acceptably. Together with the evidence of satisfactory convergent validities and reliabilities, this research indicated that our adapted BIS/BAS scales possess acceptable psychometric characteristics. However, there was limited support for the discriminant validity.

\section{REFERENCES}

Achenbach, T. M. (1991). Manual for the Child Behavior Checklist/4-18 and 1991 profile. Burlington: University of Vermont, Department of Psychiatry.

Achenbach, T. M., \& Rescorla, L. A. (2003). Mannual for ASEBA adult forms \& profiles. Burlington: University of Vermont, Research Center for Children, Youth, \& Families.

Birmaher, B., Khetarpal, S., Brent, D., Cully, M., Balach, L., Kaufman, J., \& Neer, S. M. (1997). The Screen for Child Anxiety Related Emotional Disorders (SCARED): Scale construction and psychometric characteristics. Journal of the American Academy of Child and Adolescent Psychiatry, 36, 545-553.

Bjornebekk, G. (2009). Psychometric properties of the scores on the behavioral inhibition and activation scales in a sample of Norwegian children. Psychological Measurement, 69, 636-654.

Branje, S. J. T., van Lieshout, C. F. M., \& Gerris, J. R. M. (2007). Big Five personality development in adolescence and adulthood. European Journal of Personality, 21, 45-62.
Caci, H., Deschaus, O., \& Bayle, F. J. (2007). Psychometric properties of the French versions of the BIS/BAS scales and the SPSRQ. Personality and Individual Differences, 42, 987-998.

Campbell-Sills, L., Liverant, G. I., \& Brown, T. A. (2004). Psychometric evaluation of the behavioral inhibition/behavioral activation scales in a large sample of outpatients with anxiety and mood disorders. Psychological Assessment, $16,244-254$.

Carver, C. S., \& White, T. L. (1994). Behavioral inhibition, behavioral activation, and affective responses to impending reward and punishment: The BIS/BAS scales. Journal of Personality and Social Psychology, 67, 319-333.

Chen, F. F. (2002). Sensitivity of goodness of fit indexes to lack of measurement invariance. Structural Equation Modeling, 14, 464-504.

Cheung, G. W., \& Rensvold, R. B. (2002). Evaluating goodness-of-fit indexes for testing measurement invariance. Structural Equation Modeling, 9, 233-255.

Cogswell, A., Alloy, L. B., van Dulmen, H. M., \& Fresco, D. M. (2006). A psychometric evaluation of behavioral inhibition and approach self-report measures. Personality and Individual Differences, 40, 1649-1658.

Cooper, A., Gomez, R., \& Aucote, H. (2007). The Behavioural Inhibition System and Behavioural Approach System (BIS/BAS) scales: Measurement and structural invariance across adults and adolescents. Personality and Individual Differences, 43, 295-305.

Fowles, D. C. (1987). Application of a behavioral theory of motivation to the concepts of anxiety and impulsivity. Journal of Research in Personality, 21, 417-435.

Franken, I. H. A., Muris, P., \& Rassin, E. (2005). Psychometric properties of the Dutch BIS/BAS scales. Journal of Psychopathology and Behavioral Assessment, 27, 25-30.

Gerris, J. R. M., Houtmans, M. J. M., Kwaaitaal-Roosen, E. M. G., Schipper, J. C., Vermulst, A. A., \& Janssens, J. M. A. M. (1998). Parents, adolescents and young adults in Dutch families: A longitudinal study. Nijmegen, The Netherlands: University of Nijmegen, Institute of Family Studies.

Gjone, H., \& Stevenson, J. (1997). The association between internalizing and externalizing behavior in childhood and early adolescence: Genetic or environmental common influences. Journal of Abnormal Child Psychology, 25, 277-286.

Goldberg, L. R. (1992). The development of markers for the Big Five factor structure. Psychological Assessment, 4, 26-42.

Gray, J. A. (1987). The psychology of fear and stress. New York, NY: Cambridge University Press.

Hale, W. W., Raaijmakers, Q., Muris, P., \& Meeus, W. (2005). Psychometric properties of the Screen for Child Anxiety Related Emotional Disorders (SCARED) in the general adolescent population. Journal of American Academy of Child \& Adolescent Psychiatry, 44, 283-290.

Hau, K. T., \& Marsh, H. W. (2004). The use of item parcels in structural equation modelling: Non-normal data and small sample sizes. British Journal of Mathematical Statistical Psychology, 57, 327-351.

Heubeck, B. G., Wilkinson, R. B., \& Cologon, J. (1998). A second look at Carver and White's (1994) BIS/BAS scales. Personality and Individual Differences, $25,785-800$

Hu, L. T., \& Bentler, P. M. (1999). Cutoff criteria for fit indexes in covariance structure analysis: Conventional criteria versus new alternatives. Structural Equation Modeling, 6, 1-55.

Johnson, S. L., Turner, R. J., \& Iwata, N. (2003). BIS/BAS levels and psychiatric disorder: An epidemiological study. Journal of Psychopathology and Behavioral Assessment, 25, 25-35.

Jorm, A. F., Henderson, C. A., Jacomb, P. A., Korten, A. E., \& Rodgers, B. (1999). Using the BIS/BAS scales to measure behavioural inhibition and behavioural activation: Factor structure, validity and norms in a large community sample. Personality and Individual Differences, 26, $49-58$.

Kline, R. B. (2005). Principles and practice of structural equation modeling. New York, NY: Guilford.

Knyazev, G. G., Slobodskaya, H. R., \& Wilson, G. D. (2004). Comparison of the construct validity of the Gray-Wilson personality questionnaire and the BIS/BAS scales. Personality and Individual Differences, 37, $1565-1582$. 
Leone, L., Perugini, M., Bagozzi, R. P., Pierro, A., \& Mannetti, L. (2001). Construct validity and generalizability of the Carver-White Behavioural Inhibition System/Behavioural Activation System scales. European Journal of Personality, 15, 373-390.

Lerner, R. M., \& Steinberg, L. (Eds.). (2004). Handbook of adolescent psychology. New York, NY: Wiley.

Meng, X. L., Rosenthal, R., \& Rubin, D. B. (1992). Comparing correlated correlation coefficients. Psychological Bulletin, 111, 172175 .

Müller, J. M., \& Wytykowska, A. M. (2005). Psychometric properties and validation of a Polish adaptation of Carver and White's BIS/BAS scales. Personality and Individual Differences, 39, 795-805.

Muris, P., Meesters, C., De Kanter, E. D., \& Timmerman, P. E. (2005). Behavioural Inhibition and Behavioural Activation System scales for children: Relationships with Eysenck's personality traits and psychopathological symptoms. Personality and Individual Differences, 38, 831841.

Muthén, L. K., \& Muthén, B. O. (2007). Mplus user's guide (4th ed.). Los Angeles, CA: Muthén and Muthén.

Nunnelly, J. C., \& Bernstein, I. H. (Eds.). (1994). Psychometric theory (3rd ed.). New York, NY: McGraw-Hill.

Raykov, T. (2004). Estimation of maximal reliability: A note on a covariance structure modelling approach. British Journal of Mathematical and Statistical Psychology, 57, 21-27.
Reynolds, W. M. (2002). Reynolds Adolescent Depression Scale-2nd edition: Professional manual. Odessa, FL: Psychological Assessment Resources.

Ross, S. R., Millis, S. R., Bonebright, T. L., \& Bailley, S. E. (2002). Confirmatory factor analysis of the Behavioral Inhibition and Activation Scales. Personality and Individual Differences, 33, 861-865.

Satorra, A., \& Bentler, P. M. (1994). Corrections to test statistics and standard errors in covariance structure analysis. In A. von Eye \& C. C. Clogg (Eds.), Latent variables analysis: Applications for developmental research (pp. 399-419). Thousand Oaks, CA: Sage.

Sava, F. A., \& Sperneac, A. M. (2006). Sensitivity to reward and sensitivity to punishment rating scales: A validation study on the Romanian population. Personality and Individual Differences, 41, 1445-1456.

Smillie, L. D., Jackson, C. J., \& Dalgleish, L. I. (2006). Conceptual distinctions among Carver and White's (1994) BAS scales: A reward-reactivity versus trait impulsivity perspective. Personality and Individual Differences, 40, 1039-1050.

Smits, D. J. M., \& Boeck, P. D. (2006). From BIS/BAS to the Big Five. European Journal of Personality, 20, 255-270.

Van der Linden, D., Beckers, D. G. J., \& Taris, T. W. (2007). Reinforcement sensitivity theory at work: Punishment sensitivity as a dispositional source of job-related stress. European Journal of Personality, 21, 889-909.

Verhulst, F. C., Van der Ende, J., \& Koot, H. M. (1997). Manual for the Youth SelfReport. Rotterdam, The Netherlands: Department of Child and Adolescent Psychiatry, Erasmus Medical Centre/Sophia.

\section{APPENDIX}

\section{BIS/BAS}

Name instrument BIS/BAS Scales

Construct Strength of the Behavioral Inhibition System and the Behavioral Activation System

Item number 20

Scales instrument BIS no subscales (7 items: 1, 2, 5, 9, 12, 16, 18). BAS (13) with 3 subscales: BAS-Reward (5 items: 6, 11, 15, 17, 19), BAS-Drive (4 items: 3, 7, 14, 20), BAS-Fun Seeking (4 items: 4, 8, 10, 13).

Scale type $\quad$ Range BIS: 7-28; range BAS: 13-52 (Reward Responsiveness: 5-20; Drive and Fun Seeking: 4-16)

\section{Instruction/Items}

On the next pages you will find a number of assertions. You have to read these assertions and affirm whether they are applicable to you. Next to each assertion there are four answer possibilities that vary from "totally not agree" to "totally agree." The intention is that you have to indicate with a cross in one of the shacks to what extent these assertions are applicable to you.

Don't leave any question unanswered and limit yourself to the given answer possibilities. Take your time, but don't think too long about a question.

1. When I think that something unpleasant will happen, I usually get pretty "wrought up."

2. I am worried about making mistakes.

3. When I want something, I usually completely go for it.

4. Most of the time I do things for no other reason than that it could be fun.

5. Critics or a reprimand strike me highly.

6. When I get something I want, I feel excited and charged.

7. I give great effort to get things I want.

8. I strongly desire excitement and new sensations.

9. I feel highly upset when I think or know that somebody's angry at me.

10. I am always ready to try something new if I think that it's going to be fun.

11. When I do something good, I want to continue it.

12. Even if something awful is about to happen for me, I rarely experience fear or nervousness.

13. I usually act the way the moment inspires me to do so.

14. When I see a chance to get something I want, I immediately go for it.

15. When something good happens to me, it affects me deeply.

16. I feel worried when I think that I've performed badly on something.

17. I would be excited to win a competition.

18. Compared to my friends I have very few fears.

19. If I see an opportunity to get something I like, I immediately get excited.

20. When I make work from something, I give my full self into it. 